\title{
Rancang Bangun Pemodelan Pembangkit Listrik Tenaga Mikro Hidro (PLTMH) Menggunakan Kincir Overshot Wheel
}

\author{
I Wayan Budiarsana Saputra ${ }^{1}$, Antonius Ibi Weking ${ }^{2}$, Lie Jasa ${ }^{3}$
}

\begin{abstract}
The dependence of power generation on energy sources such as diesel oil, natural gas and coal are nearly $75 \%$, led to the development of renewable energy to meet growing electricity supply. In this final project has been designed using the PLTMH modeling windmill blade overshot wheel with a semi-circular shape, wheel diameter $50 \mathrm{~cm}$, and 16 the number of blades. In this modeling water flow of $0.1 \mathrm{lt} / \mathrm{s}$ and a head of 0.6 meters. Measurements were carried out based on the position of the fall of the water to the turbine, nozzle angle of position $0^{0}, 5^{0}, 10^{0}, 15^{\circ}, 20^{0}, 25^{\circ}, 30^{\circ}, 35^{\circ}$ dan $40^{\circ}$. The results show the highest measurement on the nozzle angle of position $30^{0}$, where the output power of $0,153 \mathrm{~W}$, is $0.012 \mathrm{Nm}$ of torque turbine, and the efficiency of 0,255 . Create a small water discharge modeling performance of PLTMH is still less than the maximum, where the torque produced $0,032 \mathrm{Nm}$ generator, while the highest torque at the wheels $0,012 \mathrm{Nm}$. The percentage error torque in modeling PLTMH is $40 \%$, in modeling PLTMH efficiency percentage of this is $25.5 \%$. Comparison of torque effect on wheel rotation speed that is less able to turn a generator to the fullest.
\end{abstract}

Intisari-Ketergantungan pembangkit listrik terhadap sumber energi seperti minyak solar, gas alam dan batubara yang hampir mencapai $75 \%$, mendorong dikembangkannya energi terbarukan sebagai upaya untuk memenuhi pasokan listrik. Pada penelitian ini telah dirancang pemodelan PLTMH menggunakan kincir overshot wheel dengan bentuk sudu setengah lingkaran, diameter kincir $50 \mathrm{~cm}$, dan 16 jumlah sudu. Pada pemodelan ini debit air $0,1 \mathrm{lt} / \mathrm{s}$ dan head 0,6 meter. Pengukuran yang dilakukan berdasarkan posisi jatuhnya air terhadap kincir, dari posisi sudut nozzle $0^{0}, 5^{0}, 10^{0}, 15^{0}, 20^{0}, 25^{0}$, $30^{\circ}, 35^{\circ}$ dan $40^{\circ}$. Diperoleh hasil pengukuran tertinggi pada sudut nozzle $30^{\circ}$, dimana daya output $0,153 \mathrm{~W}$, torsi kincir $0,012 \mathrm{Nm}$, dan efisiensi 0,255. Debit air yang kecil membuat kinerja pemodelan PLTMH ini masih kurang maksimal, dimana torsi yang dihasilkan generator $0,032 \mathrm{Nm}$ sedangkan torsi tertinggi pada kincir $0,012 \mathrm{Nm}$. Persentase error torsi pada pemodelan PLTMH ini adalah $40 \%$, untuk persentase efisiensi dari pemodelan PLTMH ini adalah 25,5\%. Perbandingan torsi berpengaruh terhadap kecepatan putaran kincir yang kurang mampu untuk memutar generator secara maksimal.

Kata Kunci-PLTMH, Sudut Nozzel, Debit Air, Torsi, Efisiensi

${ }^{1}$ Mahasiswa, Jurusan Teknik Elektro dan Komputer Fakultas Teknik Universitas Udayana, Br. Teges Kawan, Peliatan, Ubud, Gianyar80571(Hp:082339326540;email:saputraarsana@yahoo .co.id)

${ }^{3}$ Staf Pengajar Jurusan Teknik Elektro dan Komputer Fakultas Teknik Universitas Udayana, Jalan Kampus Bukit Jimbaran 80361 INDONESIA (telp: 0361-703315; fax: 03614321)

\section{Pendahuluan}

Ketergantungan pembangkit listrik terhadap sumber energi seperti minyak solar, gas alam dan batubara yang hampir mencapai $75 \%$, mendorong dikembangkannya energi terbarukan sebagai upaya untuk memenuhi pasokan listrik [1]. Salah satunya adalah pada pembangkit listrik tenaga mikro hidro dengan memanfaatkan potensi air yang ada. Prinsip kerja PLTMH adalah dengan cara merubah energi potensi air menjadi energi listrik.[2]

Penelitian ini telah dirancang pemodelan pembangkit listrik tenaga mikro hidro dengan menggunakan kincir overshot wheel. Kincir yang digunakan memiliki bentuk sudu setengah lingkaran, dengan diameter kincir $50 \mathrm{~cm}$, lebar kincir $10 \mathrm{~cm}$, dan jumlah sudu 16 buah. Pengukuran yang dilakukan pada pemodelan pembangkit listrik tenaga mikro hidro ini, meliputi : debit air, tekanan air, putaran kincir, putaran generator, tegangan, arus, serta daya output generator dan torsi serta efisiensi. Parameter - parameter tersebut diukur dengan cara merubah jatuhnya air pada kincir dari posisi sudut nozzle $0^{\circ}, 5^{\circ}, 10^{\circ}, 15^{\circ}, 20^{\circ}, 25^{\circ}, 30^{\circ}, 35^{\circ}$ dan $40^{\circ}$. Dari parameter yang diukur serta pengujian pada pemodelan PLTMH, dapat diketahui kinerja dan persentase error dari pemodelan PLTMH yang dirancang.

\section{MODEL PLTMH}

\section{A. Pengertian Pembangkit Listrik Tenaga Mikro Hidro}

Pembangkit listrik tenaga mikro hidro (PLTMH) adalah suatu pembangkit listrik berskala kecil yang menggunakan tenaga air sebagai penggeraknya, misalnya saluran irigasi, sungai atau air terjun alam dengan cara memanfaatkan tinggi terjunnya air (head) dan jumlah debit air maupun tekanan airnya.

Prinsip kerja PLTMH adalah memanfaatkan beda tinggi head dan jumlah debit air per detik yang ada pada aliran atau sungai. Air yang mengalir melalui intake diteruskan oleh saluran pembawa hingga penstock, yang kemudian akan memutar poros turbin sehingga menghasilkan energi mekanik. Turbin air akan memutar generator dan menghasilkan energi listrik.[3]

\section{B. Bagian - bagian Pembangkit Listrik Tenaga Mikro Hidro}

1) Bangunan Pemasok Air: Pada umumnya bangunan pemasok air pada PLTMH adalah bangunan terjun (air terjun) dan saluran irigasi yang memiliki potensi air tinggi. [4]

2) Bak Penenang: Bak penenang berfungsi menampung aliran air dari saluran irigasi sebagai cadangan kekurangan debit air yang akan digunakan, untuk kemudian dialirkan melalui pipa pesat. [5] 
3) Pipa Pesat: Syarat - syarat pipa pesat harus dapat bertugas sebagai pengantar air dan tidak bocor serta harus dapat mengimbangi tekanan air. [6]

4) Turbin: Turbin merupakan bagian penting dari sistem mikro hidro yang menerima energi potensial dari air dan mengubahnya menjadi energi mekanik (putaran). Kemudian energi mekanik ini akan memutar sumbu turbin pada generator. [7]

5) Generator: Berdasarkan arus yang dihasilkan, generator dapat dibedakan menjadi dua rnacam, yaitu generator AC dan generator DC. Generator AC menghasilkan arus bolak-balik (AC) dan generator DC menghasilkan arus searah (DC). Baik arus bolak-balik maupun searah dapat digunakan untuk penerangan dan alat-alat pemanas. [8]

\section{Potensi Air}

Air yang mengalir mempunyai energi yang dapat digunakan untuk memutar roda turbin, karena itu pusat - pusat tenaga air dibangun di sungai dan didaerah pegunungan. Pusat tenaga air tersebut dapat dibedakan dalam 2 golongan, yaitu pusat tenaga air tekanan tinggi dan pusat tenaga air tekanan rendah. Aliran air yang jatuh dengan debit $Q\left(\mathrm{~m}^{3} / \mathrm{s}\right)$ yang mengenai kincir atau turbin air akan menghasilkan daya sebesar [9] :

$$
P=\rho \cdot Q \cdot g \cdot H
$$

Dimana :

$\mathrm{P}=$ Daya $(\mathrm{W})$

$\rho=$ Kerapatan Air $\left(1000 \mathrm{~kg} / \mathrm{m}^{3}\right)$

$\mathrm{Q}=$ Debit Air $\left(\mathrm{m}^{3} / \mathrm{s}\right)$

$g=$ Gravitasi Bumi $\left(9,81 \mathrm{~m} / \mathrm{s}^{2}\right)$

$\mathrm{H}=$ Ketinggian Jatuh Air (m)

Setelah diperoleh daya, dapat diketahui efisiensi dari pembangkit listrik tenaga mikro hidro sebagai berikut :

$$
\eta=\frac{\text { Pin }}{\text { Pout }}
$$

Dimana :

$\eta=$ Efisiensi

$\mathrm{P}_{\mathrm{In}}=$ Daya Kincir $(\mathrm{W})$

$\mathrm{P}_{\text {Out }}=$ Daya Generator $(\mathrm{W})$

Untuk menghitung torsi dapat dilakukan dengan persamaan :

$$
T=\frac{P}{2 \pi \frac{n}{60}}
$$

Dimana :

$\mathrm{T}=$ Torsi $(\mathrm{Nm})$

$\mathrm{P}=$ Daya $(\mathrm{W})$

$\mathrm{n}=$ Putaran $(\mathrm{rpm})$

\section{Turbin Air}

Turbin air adalah peralatan yang berfungsi mengubah energi kinetik yang dimiliki aliran air menjadi energi kinetik rotasi [10]. Turbin berfungsi mengubah energi potensial fluida menjadi energi mekanik yang kemudian diubah lagi menjadi energi listrik pada generator. [11]
Adapun perbandingan karakteristik turbin dapat kita lihat pada gambar 1.

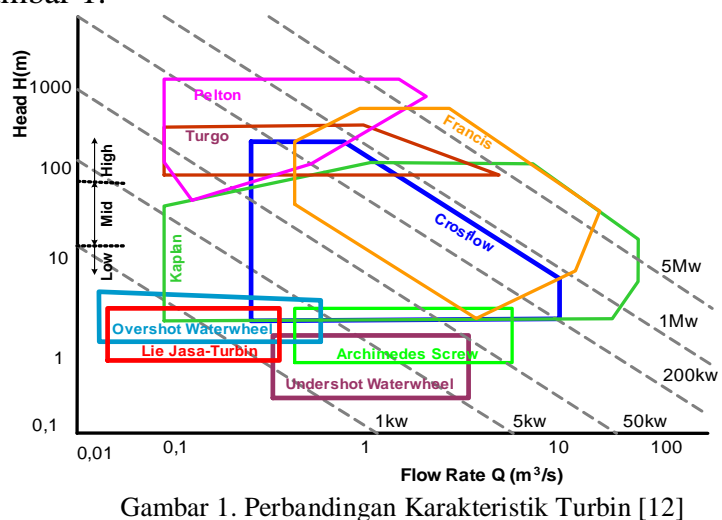

\section{E. Kincir Air}

Bagian ini digunakan untuk merubah energi air yang mengalir menjadi energi kinetis dalam bentuk energi putaran, semakin besar air yang memutar kincir semakin besar momen energi putar yang didapat. Tentunya disamping volume air juga tekanan air yang jatuh mempercepat putaran kincir sehingga momen putaran akan makin besar, diharapkan mampu memutar puli - puli yang dihubungkan dengan tali kipas (vent belt) untuk memutar generator. [13]

Ada tiga tipe kincir air dari bagaimana air dimanfaatkan, antar lain [14]:

1) Overshot Wheel: kincir air dimana posisi disalurkannya air ke roda bagian atas kincir. Pada kincir air model ini ketinggian air $(\mathrm{H})$ harus lebih besar dari diameter roda. Kincir air jenis ini, perbedaan ketinggiannya antara 2,5 $10 \mathrm{~m}$ dan debit air (Q) antara $0,1-0,2 \mathrm{~m}^{3} / \mathrm{s}$ per $\mathrm{m}$ lebar.

2) Breast wheel: kincir air dimana posisi disalurkannya air ke dalam roda sejajar dengan poros kincir (breast). Kincir air jenis ini perbedaan ketinggiannya antara 1,5 - $4 \mathrm{~m}$ dengan debit air (Q) antara $0,35-0,65 \mathrm{~m}^{3} / \mathrm{s}$ per $\mathrm{m}$ lebar.

3) Undershot wheel: kincir air dimana posisi disalurkannya air ke dalam roda pada bagian bawah dari kincir. Seperti ditunjukkan pada gambar 2.10. Beda ketinggian permukaan air pada jenis kincir ini rendah. Perbedaan ketinggian dari kincir jenis ini antara 0,5 - 2,5 m dengan debit air (Q) antara $0,5-0,95 \mathrm{~m}^{3} / \mathrm{s}$ per $\mathrm{m}$ lebar.

\section{F. Kriteria Pemilihan Jenis Turbin}

Pemilihan jenis turbin dapat diperhitungkan dengan mempertimbangkan parameter - parameter khusus yang mempengaruhi sistem operasi turbin, yaitu :

1) Faktor tinggi jatuhnya air dan debit yang dimanfaatkan untuk operasi turbin.

2) Faktor daya yang diinginkan berkaitan dengan head dan debit yang tersedia.

3) Kecepatan putaran turbin yang akan ditransmisikan ke generator. 


\section{METODE PERANCANGAN}

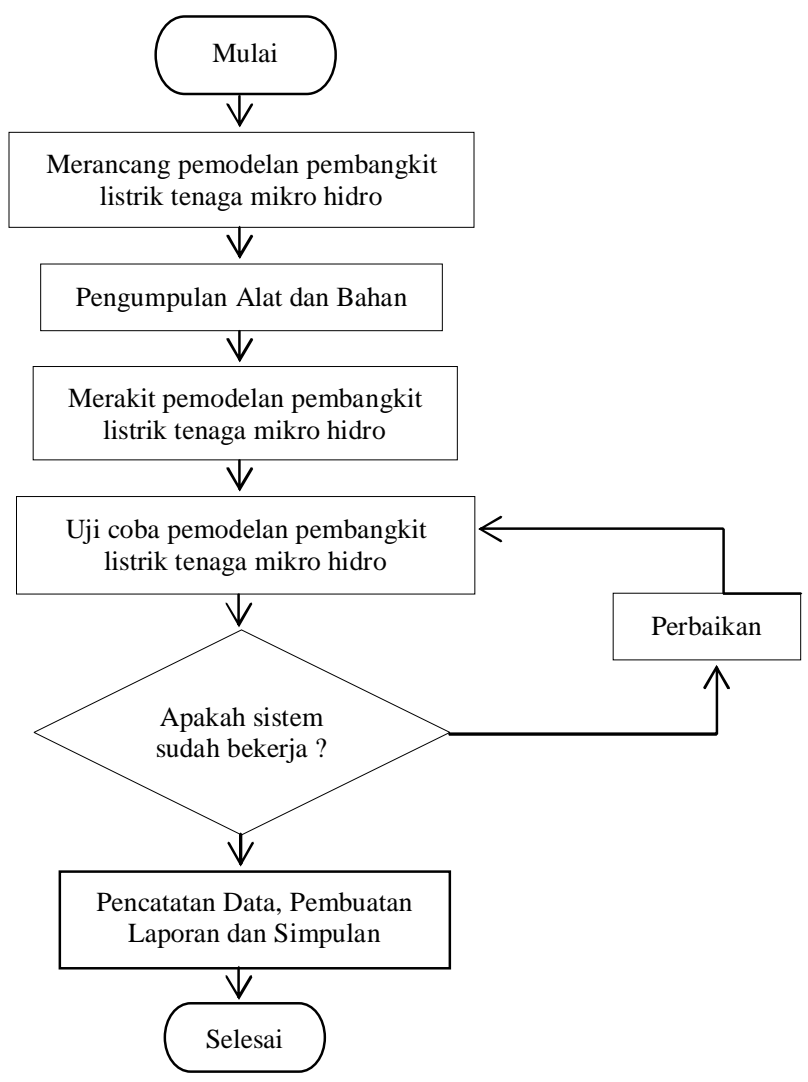

Gambar 2. Diagram Alir Penelitian Pemodelan PLTMH

\section{A. Merancang Pemodelan PLTMH}

Perancangan pada pemodelan PLTMH ini meliputi perancangan sistem PLTMH dan perancangan kincir yang digunakan. Perancangan sistem PLTMH antara lain : volume box 330 liter, ketinggian jatuh air 0,6 meter, panjang pipa 160 $\mathrm{cm}$, dan diameter pia $3 / 4$ dan $1 \mathrm{dim}$, untuk pompa yang digunakan menghasilkan debit (Q) sebesar $10-28 \mathrm{lt} / \mathrm{min}$ atau $0,16-0,46 \mathrm{lt} / \mathrm{s}$. Perancangan kincir meliputi : diameter kincir dibuat $50 \mathrm{~cm}$, lebar kincir $10 \mathrm{~cm}$, sudu kincir berbentuk setengah lingkaran dan jumlah sudu 16.

\section{B. Pengumpulan Alat Dan Bahan}

Pengumpulan alat seperti acrilic sebagai bahan kincir, aluminium sebagai rangka PLTMH, pemilihan jenis box, generator, pipa, pompa dll. Menyiapkan alat yang diperlukan untuk merakit pemodelan PLTMH.

\section{Merakit Desain Pemodelan PLTMH}

Perakitan pemodelan PLTMH direncakan seperti pada gambar 3. Desain pemodelan PLTMH meliputi : kincir overshot wheel dengan sudu berbentuk setengah lingkaran, pompa air, generator berkapasitas kecil (dinamo sepeda), curat (nozzel), pipa PVC, pillow, rangka dari bahan aluminium.

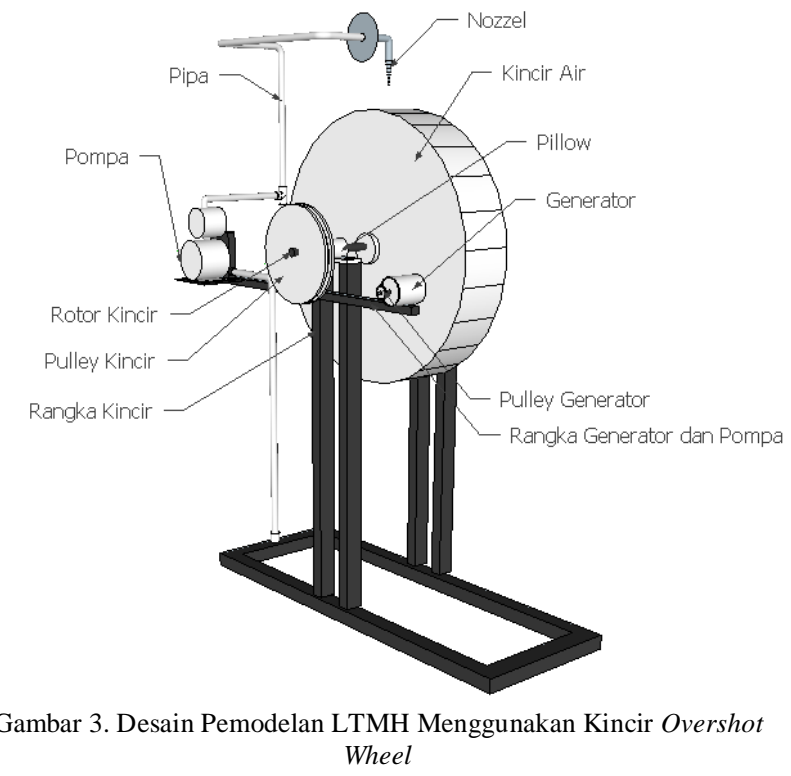

D. Cara kerja pemodelan PLTMH

Cara kerja pemodelan PLTMH menggunakan kincir overshot ini dapat dilihat pada gambar 4.

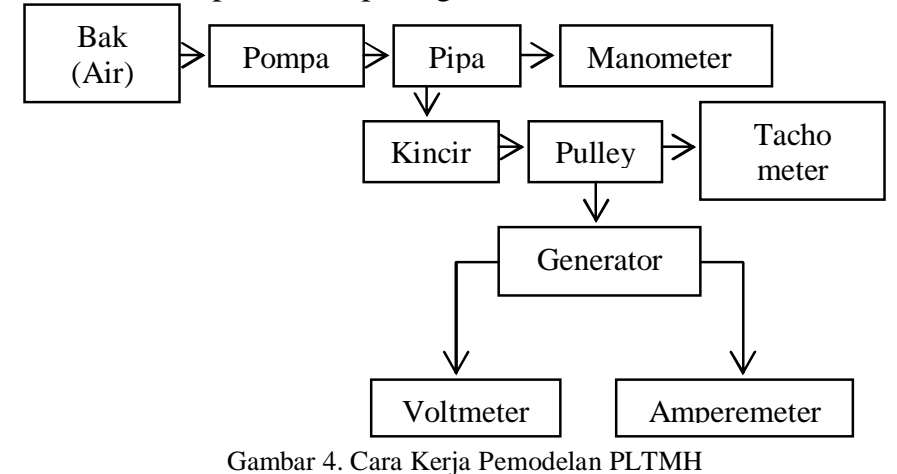

Penjelasan dari cara kerja pemodelan PLTMH yaitu, Pertama pompa akan menghisap air yang terdapat pada bak, kemudian air dialirkan melalui pipa sampai ke sudu kincir hingga kincir berputar. Terjadi energi mekanik saat kincir berputar, kincir terhubung dengan pulley kincir melalui sebuah poros. Dengan sebuah belt, pulley kincir dihubungkan dengan pulley yang terhubung pada rotor generator (pulley generator). Putaran yang terjadi pada kincir akan memutar generator melalui kedua pulley yang terhubung. Generator akan merubah energi mekanik dari kincir menjadi energi listrik. Pada pipa akan dipasang pressure gauge untuk mengukur tekanan air. Untuk mengukur putaran kincir dan generator dipergunakan tachometer. Sedangkan voltmeter dan amperemeter dipergunakan untuk mengukur tegangan dan arus yang dihasilkan oleh generator.

\section{E. Pencatatan Data Pemodelan PLTMH}

Pengukuran pada pemodelan PLTMH ini diukur dengan cara merubah jatuhnya air pada kincir dari posisi sudut nozzle $0^{0}, 5^{0}, 10^{\circ}, 15^{0}, 20^{\circ}, 25^{\circ}, 30^{\circ}, 35^{\circ}$ dan $40^{\circ}$, posisi sudut nozzle dapat dilihat pada gambar 5. Parameter yang akan diukur 
Teknologi Elektro, Vol. 16, No. 02, Mei - Agustus 2017 meliputi : debit air, tekanan air, putaran kincir, putaran generator, tegangan, arus, serta daya output generator dan torsi serta efisiensi. Untuk pengukuran tegangan, arus dan daya output dilakukan pengukuran tanpa beban dan dengan beban lampu 3 watt.
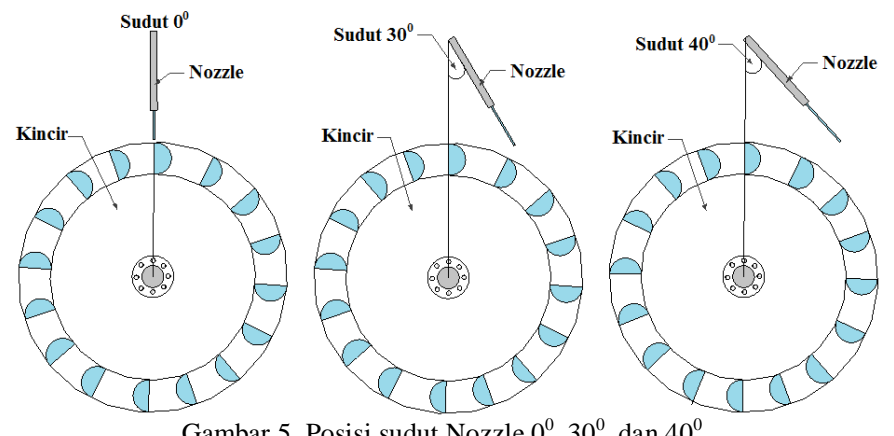

Gambar 5. Posisi sudut Nozzle $0^{\circ}, 30^{\circ}$, dan $40^{\circ}$

\section{HASIL DAN PEMBAHASAN}

\section{A. Realisasi Hasil Perancangan}

Realisasi hasil perancangan PLTMH menggunakan kincir overshot wheel dapat dilihat pada gambar 6. Gambar 6 merupakan realisasi menyeluruh pemodelan PLTMH, dimana semua komponen telah digabung menjadi satu kesatuan pemodelan PLTMH.

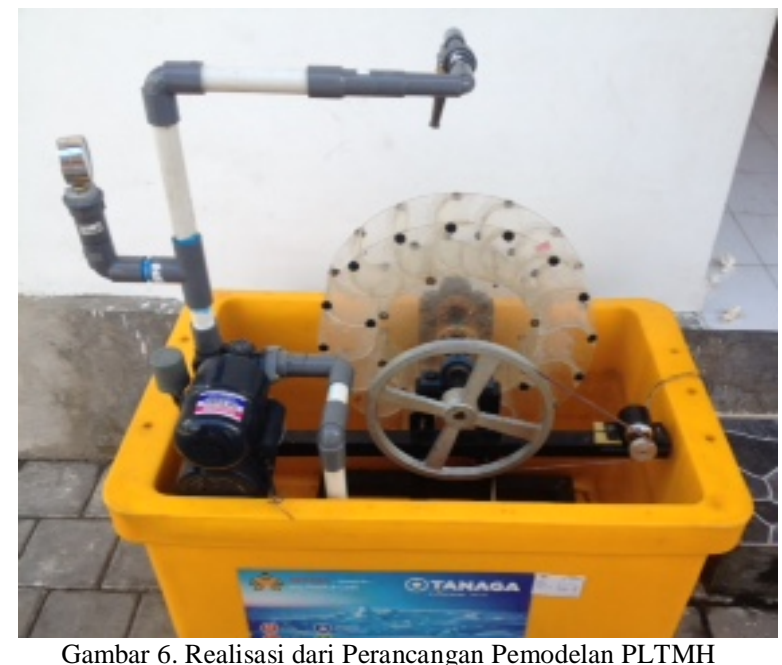

\section{B. Pengukuran Debit Air}

Debit air adalah besaran yang menyatakan banyaknya air yang mengalir selama satu detik yang melewati suatu penampang luas. Bejana yang digunakan untuk pengujian memiliki volume 7,6 liter dan waktu untuk memenuhi bejana adalah 74,88 detik, sehingga pengukuran debit dapat dihitung sebagai berikut :

$$
\begin{aligned}
Q & =\frac{7,6}{74,88} \\
& =0,1 \mathrm{lt} / \mathrm{s}
\end{aligned}
$$

Dari nilai debit yang diperoleh pada saat pengujian, dapat dihitung daya output kincir sebagai berikut :

$$
\begin{aligned}
P & =1000 * 0,0001 * 9,81 * 0,6 \\
& =0,6 \mathrm{watt}
\end{aligned}
$$

Untuk pengukuran tekanan air diperoleh hasil berturut turut dari sudut nozzle $0^{\circ}, 5^{\circ}, 10^{\circ}, 15^{\circ}, 20^{\circ}, 25^{\circ}, 30^{\circ}, 35^{\circ}$ dan $40^{\circ}$ adalah $25 \mathrm{~kg} / \mathrm{cm}^{2}$.

\section{Pengukuran Menyeluruh Pada PLTMH}

Hasil pengukuran parameter - parameter pada pemodelan PLTMH dari sudut nozzel $0^{0}, 5^{\circ}, 10^{\circ}, 15^{\circ}, 20^{\circ}, 25^{\circ}, 30^{\circ}, 35^{\circ}$ dan $40^{\circ}$ berturut - turut dapat dilihat pada tabel 1 , serta hubungan antara sudut nozzle dengan parameter - parameter

\begin{tabular}{|c|c|c|c|c|c|c|c|}
\hline \multirow[t]{2}{*}{$\begin{array}{l}\text { Sudut } \\
\text { nozzel }\end{array}$} & \multicolumn{2}{|c|}{$\begin{array}{c}\text { Putaran kincir } \\
\text { (rpm) }\end{array}$} & \multirow{2}{*}{$\begin{array}{l}\text { Putaran } \\
\text { generator } \\
(\mathbf{r p m})\end{array}$} & \multirow{2}{*}{$\begin{array}{c}\begin{array}{c}\text { Tanpa } \\
\text { Beban }\end{array} \\
\mathbf{V} \\
(\mathrm{v})\end{array}$} & \multicolumn{3}{|c|}{ Lampu 3 watt } \\
\hline & $\begin{array}{c}\begin{array}{c}\text { Sebelum } \\
\text { dikopel }\end{array} \\
\end{array}$ & $\begin{array}{l}\text { Setelah } \\
\text { dikopel }\end{array}$ & & & $\begin{array}{l}\mathrm{V} \\
(\mathrm{v})\end{array}$ & $\begin{array}{c}\mathbf{I} \\
(\mathbf{m A})\end{array}$ & $\begin{array}{c}\mathbf{P} \\
(\mathbf{W})\end{array}$ \\
\hline $0^{0}$ & 0 & 0 & 0 & 0 & 0 & 0 & 0 \\
\hline $5^{0}$ & 0 & 0 & 0 & 0 & 0 & 0 & 0 \\
\hline $10^{0}$ & 97 & 33 & 187 & 1,15 & 0,21 & 57 & 0,012 \\
\hline $15^{0}$ & 135 & 46 & 352 & 1,5 & 0,32 & 79 & 0,025 \\
\hline $20^{\circ}$ & 192 & 76 & 489 & 2,4 & 0,68 & 104 & 0,071 \\
\hline $25^{0}$ & 219 & 106 & 644 & 3,3 & 1,04 & 123 & 0,128 \\
\hline $30^{\circ}$ & 287 & 122 & 718 & 3,5 & 1,15 & 132 & 0,153 \\
\hline $35^{0}$ & 201 & 81 & 511 & 2,5 & 0,70 & 110 & 0,077 \\
\hline $40^{\circ}$ & 0 & 0 & 0 & 0 & 0 & 0 & 0 \\
\hline
\end{tabular}
pemodelan PLTMH dapat dilihat pada gambar 7, 8 dan 9.

TABEL 1

PENGUKURAN PUTARAN KINCIR

Dari hasil pengukuran yang telah dilakukan dapat dilihat hasil tertinggi pada putaran kincir, putaran generator, tegangan, arus dan daya diperoleh pada sudut nozzle $30^{\circ}$. Hal tersebut dikarenakan air yang keluar dari nozzle mengenai daerah kincir yang paling aktif pada sudut nozzle $30^{\circ}$, namun pada sudut nozzle $35^{\circ}$ terjadi penurunan hasil dari seluruh parameter yang ada dikarenakan air sudah tidak lagi mengenai daerah paling aktif pada kincir. Sementara pada sudut nozzle $40^{\circ}$ air yang keluar dari nozzle sudah tidak mengenai bagian kincir, sehingga kincir tidak berputar. Untuk sudut nozzle $0^{0}$ dan $5^{0}$ kincir juga dianggap tidak berputar, karena putaran kincir pada sudut $0^{0}$ dan $5^{0}$ terjadi saat air memenuhi sebuah sudu kincir saja, jadi putaran kincir tidak konstan.

\section{1) Hubungan Sudut Nozzel Dengan Putaran Kincir}

Hasil pengukuran putaran kincir sebelum maupun setelah dikopel dengan generator menunjukkan rpm tertinggi didapat pada posisi sudut nozzle di $30^{\circ}$. Karena pada sudut nozzel $30^{\circ}$ aliran air yang keluar dari nozzel mengenai sudu kincir yang paling aktif berputar. Sebelum dikopel dengan generator hasil pengukuran putaran kincir pada sudut nozzel $30^{\circ}$ diperoleh $287 \mathrm{rpm}$, sedangkan setelah dikopel dengan generator diperoleh $122 \mathrm{rpm}$. Pada saat sudut nozzle $40^{\circ}$ kincir tidak

I Wayan Budiarsana Saputra: Rancang Bangun Pembangkit Listrik ... 
berputar dikarenakan air yang keluar dari nozzle sudah tidak lagi mengenai kincir, sama halnya untuk sudut nozzle $0^{0}$ dan $5^{0}$ karena kincir tidak berputar secara konstan dan maka dianggap tidak berputar. Hubungan sudut nozzle dengan putaran kincir dapat dilihat pada gambar 7 .

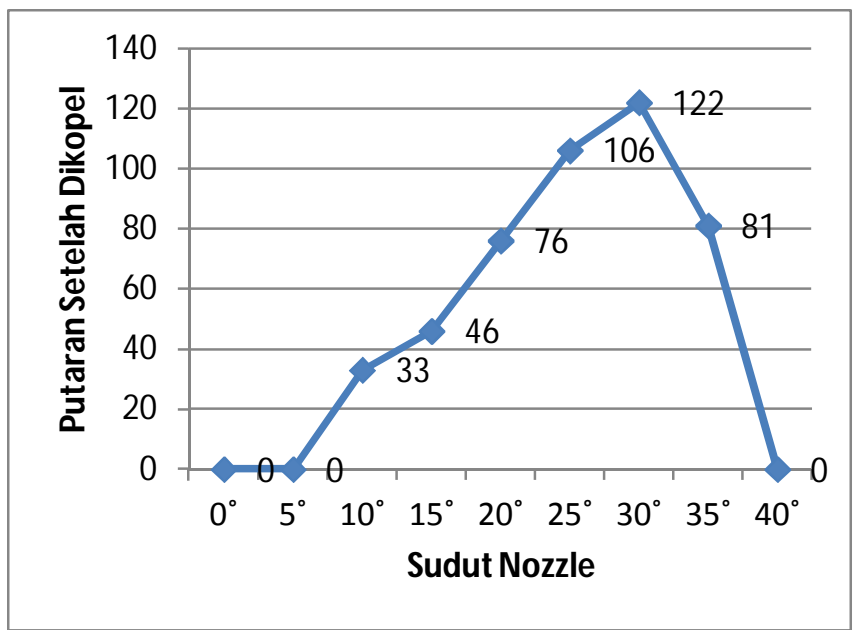

Gambar 7. Hubungan Sudut Nozzle Dengan Putaran Kincir Setelah Dikopel

\section{2) Hubungan Sudut Nozzle Dengan Putaran Generator}

Hasil pengukuran putaran generator menunjukkan putaran tertinggi pada sudut nozzle $30^{\circ}$, karena pada pengukuran putaran kincir rpm tertinggi juga terukur pada sudut $30^{\circ}$. Putaran generator tertinggi pada sudut $30^{\circ}$ adalah $718 \mathrm{rpm}$, nilai tersebut didapat karena rasio pulley antara kincir dan generator adalah $1: 5$. Pada saat sudut nozzle $40^{\circ}$ kincir tidak berputar dikarenakan air yang keluar dari nozzle sudah tidak lagi mengenai kincir, sama halnya untuk sudut nozzle $0^{0}$ dan $5^{0}$ karena kincir tidak berputar secara konstan dan dianggap tidak berputar, maka generator juga dianggap tidak berputar. Hubungan sudut nozzle dengan putaran generator dapat dilihat pada gambar 8 .

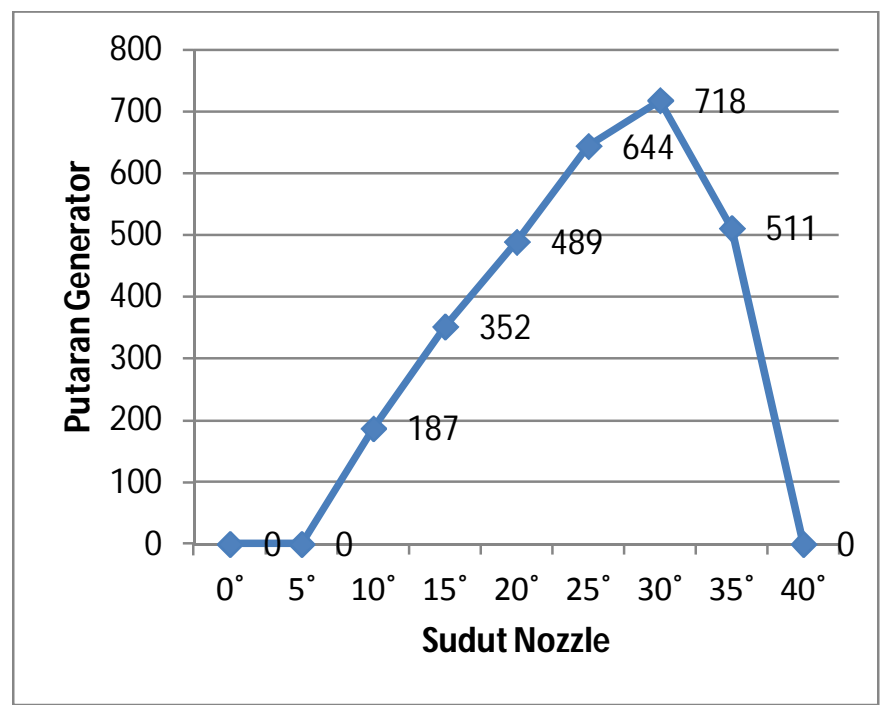

Gambar 8. Hubungan Sudut Nozzel Dengan Putaran Generator

\section{3) Hubungan Sudut Nozzle Dengan Daya Output}

Hasil pengukuran daya generator yang dilakukan pada saat generator diberikan beban lampu 3 watt. Hasil pengukuran daya generator diperoleh dari hasil perkalian (Tegangan * Arus) generator yang terukur. Pada pengukuran daya generator, daya tertinggi diperoleh pada pemodelan pembangkit listrik tenaga mikro hidro saat sudut nozzel $30^{\circ}$ dengan nilai daya 0,1560 watt. Pada sudut nozzle $35^{\circ}$ daya yang dihasilkan generator menurun. Pada sudut nozzle $20^{\circ}$, $25^{\circ}$, dan $30^{\circ}$ lampu dapat menyala namun redup, dan Pada sudut nozzle $35^{\circ}$ walaupun daya generator menurun tapi lampu tetap menyala namun redup. Hubungan sudut nozzle dengan daya output dapat dilihat pada gambar 9 .

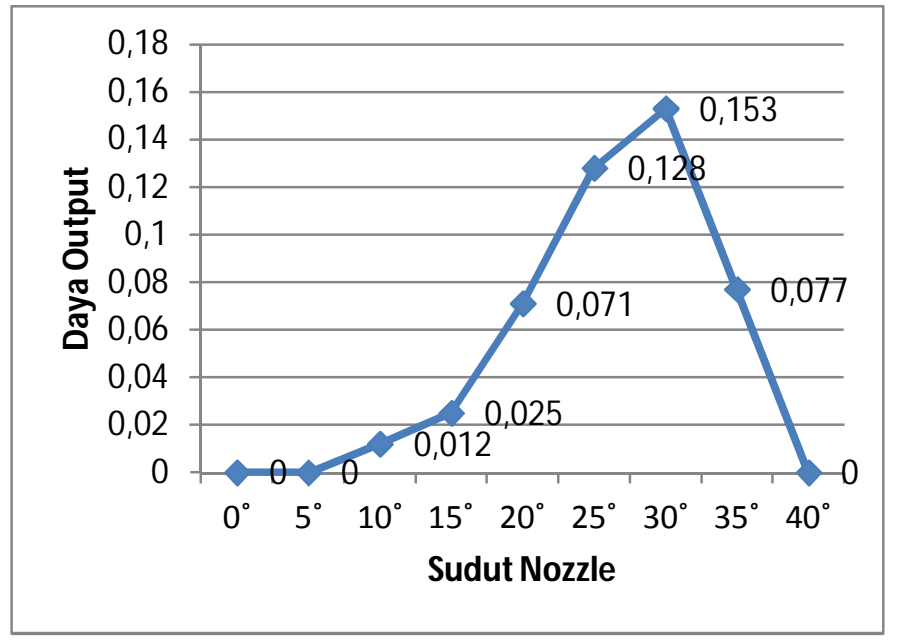

Gambar 9. Hubungan Sudut Nozzel Dengan Daya Output Generator

\section{Perhitungan Torsi}

Dari pengukuran yang telah dilakukan dapat dikatakan kincir kurang mampu memutar atau memberikan tenaga pada generator sehingga generator tidak menghasilkan daya output yang maksimal.

Daya nominal generator adalah 6 watt dan kecepatan putaran nominal generator adalah $1800 \mathrm{rpm}$, maka torsi pada generator dapat dihitung sebagai berikut :

$$
\begin{aligned}
T & =\frac{6}{2 * 3,14 * \frac{1800}{60}} \\
& =0,032 \mathrm{Nm}
\end{aligned}
$$

Daya output dan kecepatan putaran kincir berbeda setiap pergantian sudut nozzelnya, untuk keseluruhan perhitungan torsi pada setiap sudut nozzle dapat dilihat pada tabel 2 . Perhitungan torsi kincir pada sudut nozzle $30^{\circ}$ dapat dihitung sebagai berikut :

$$
\begin{aligned}
T & =\frac{0,153}{2 * 3,14 * \frac{122}{60}} \\
& =0,012 \mathrm{Nm}
\end{aligned}
$$


PERHITUNGAN TORSI

\begin{tabular}{|c|c|}
\hline Sudut Nozzle & Torsi $\mathbf{( N m )}$ \\
\hline $0^{0}$ & 0 \\
\hline $5^{0}$ & 0 \\
\hline $10^{0}$ & 0,0035 \\
\hline $15^{0}$ & 0,0052 \\
\hline $20^{0}$ & 0,0089 \\
\hline $25^{0}$ & 0,0115 \\
\hline $30^{0}$ & 0,012 \\
\hline $35^{0}$ & 0,0094 \\
\hline $40^{0}$ & 0 \\
\hline
\end{tabular}

Dari perhitungan yang telah dilakukan, diperoleh torsi terbesar pada sudut nozzel $30^{\circ}$ adalah $0,012 \mathrm{Nm}$. Kecepatan putaran kincir yang lebih rendah dari kecepatan putaran generator akan menghasilkan torsi yang cukup untuk memutar generator.

\section{E. Analisis Pemodelan PLTMH}

Putaran kincir yang kurang mampu memutar generator menyebabkan daya output yang kecil. Agar kincir dapat memutar generator secara optimal, dapat dilakukan dengan cara :

1) Torsi kincir dibuat $0,032 \mathrm{Nm}$, dengan kecepatan putaran yang tetap

Karena memiliki kecepatan putaran tertinggi sebagai contoh kecepatan putaran kincir yang digunakan adalah pada saat sudut nozzle $30^{\circ}$ :

$$
\begin{aligned}
P & =0,032 \times 2 \pi \times \frac{122}{60} \\
& =0,40 \mathrm{watt}
\end{aligned}
$$

Agar kincir dapat menghasilkan torsi 0,032 $\mathrm{Nm}$ dan daya sebesar 0,40 watt maka ketinggian jatuh air $(\mathrm{H})$ dan kapasitas aliran air (Q) harus diubah agar dapat menghasilkan daya yang diinginkan.

$$
\begin{aligned}
0,40 & =(1000) *(Q) *(9,81) *(H) \\
(Q)(H) & =0,00004
\end{aligned}
$$

Jika nilai ketinggian jatuh air $(\mathrm{H})$ tetap, maka nilai debit air (Q) harus dirubah.

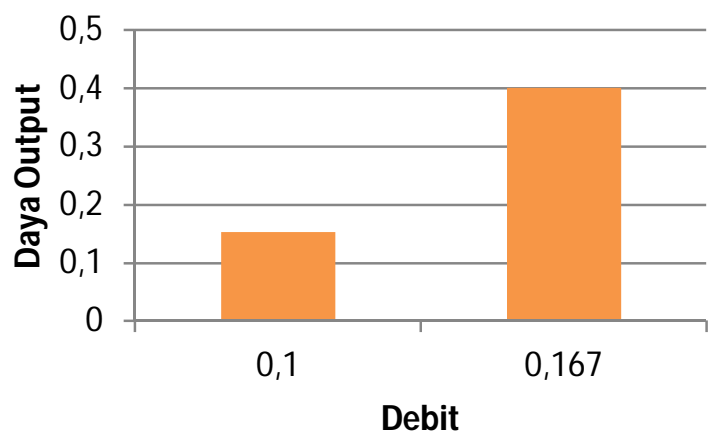

Gambar 10. Perbandingan Debit Terhadap Daya Output

I Wayan Budiarsana Saputra: Rancang Bangun Pembangkit Listrik ...
Dari gambar 10 dapat diketahui untuk mendapatkan nilai torsi $0,032 \mathrm{Nm}$ dan daya output 0,4 watt, maka nilai debit air (Q) harus diperbesar dari 0,1 lt/s menjadi 0,167 lt/s.

Dari hasil pengukuran serta pengujian yang dilakukan pada pemodelan pembangkit listrik tenaga mikro hidro ini, diketahui aliran air atau debit yang dihasilkan adalah $0,1 \mathrm{lt} / \mathrm{s}$. Debit tersebut kurang mampu memutar kincir dan generator untuk menghasilkan daya output yang maksimal. Untuk memutar kincir serta generator agar menghasilkan daya output yang maksimal dibutuhkan aliran air atau debit sebesar 0,167 $l t / s$. Dari selisih aliran air atau debit tersebut dapat diperoleh persentase error, yaitu :

$$
\begin{aligned}
\% \text { error } & =\frac{0,167-0,1}{0,167} \times 100 \% \\
& =40 \%
\end{aligned}
$$

Jika nilai debit air $(\mathrm{Q})$ tetap, maka nilai ketinggian jatuh air $(\mathrm{H})$ harus dirubah.

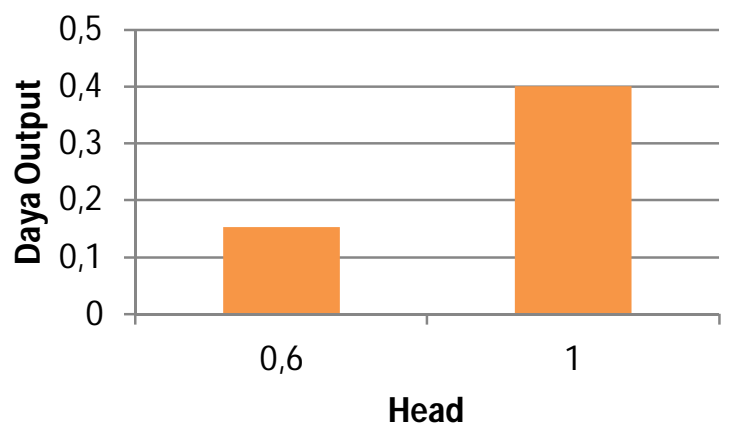

Gambar 11. Perbandingan Head Terhadap Daya Output

Dari gambar 11 dapat dilihat untuk mendapatkan nilai torsi $0,032 \mathrm{Nm}$ dan daya output 0,4 watt, maka nilai ketinggian jatuh air $(\mathrm{H})$ harus diperbesar dari 0,6 m menjadi $1 \mathrm{~m}$.

Dari hasil pengukuran serta pengujian yang dilakukan pada pemodelan pembangkit listrik tenaga mikro hidro ini, diketahui ketinggian jatuh air yang adalah 0,6 meter. Head tersebut kurang mampu memutar kincir dan generator untuk menghasilkan daya output yang maksimal. Sedangkan untuk memutar kincir serta generator agar menghasilkan daya output yang maksimal dibutuhkan ketinggian jatuh air dengan tinggi 1 meter. Dari selisih ketinggian jatuh air tersebut dapat diperoleh persentase error, yaitu :

$$
\begin{aligned}
\% \text { error } & =\frac{1-0,6}{1} \times 100 \% \\
& =40 \%
\end{aligned}
$$

2) Torsi kincir dibuat $0,032 \mathrm{Nm}$, dengan daya output turbin yang tetap

Sebagai ilustrasi daya output yang digunakan adalah pada saat sudut nozzle $30^{\circ}$, dimana nilai daya output pada sudut nozzle $30^{\circ}$ adalah 0,153 watt. Torsi kincir dibuat agar bernilai $0,032 \mathrm{Nm}$ dengan daya output yang tetap yaitu 0,153 watt, sehingga nilai ketinggian jatuh air $(\mathrm{H})$ dan nilai debit air $(\mathrm{Q})$ tidak dirubah.

$$
0,153=0,00053 \times 2 \pi \times \frac{n}{60}
$$

$$
\text { p-ISSN:1693 - 2951; e-ISSN: 2503-2372 }
$$




$$
\begin{aligned}
\frac{n}{60} & =\frac{0,153}{0,032 \times 2 \pi} \\
n & =45,6
\end{aligned}
$$

Pada pengukuran putaran kincir dan putaran generator, rasio pulley yang digunakan adalah $5: 1$. Pada sudut nozzle $30^{\circ}$ putaran kincir diperoleh $122 \mathrm{rpm}$, sedangkan putaran generator $718 \mathrm{rpm}$. Pada analisi ini untuk memperoleh torsi 0,032 Nm, diperlukan kecepatan kincir 45,6 rpm untuk memutar generator hingga $718 \mathrm{rpm}$. Sehingga dibutuhkan perbandingan rasio pulley $15: 1$ antara putaran kincir dengan putaran generator.

\section{F. Efisiensi Pemodelan PLTMH}

Efisiensi pada pemodelan PLTMH ini diperoleh dari hasil bagi daya output dengan daya input. Daya output tertinggi pemodelan ini adalah 0,153 watt pada sudut nozzle $30^{\circ}$, sedangkan daya input adalah 0,6 watt, sehingga efisiensi pemodelan PLTMH ini adalah :

$$
\begin{aligned}
\eta & =\frac{\text { Pout }}{\text { Pin }} \\
& =\frac{0,153}{0,6} \\
& =0,255
\end{aligned}
$$

Jadi efisiensi pemodelan PLTMH ini adalah 0,255 atau $25,5 \%$.

\section{KESIMPULAN}

Kesimpulan dari penelitian ini adalah sebagai berikut :

1. Telah dibangun pembangkit listrik tenaga mikro hidro yang menggunakan kincir overshot wheel berbentuk setengah lingkaran dengan jumlah sudu 16 buah. Dengan sudut jatuhnya air atau sudut nozzle mulai dari $0^{\circ}, 5^{\circ}, 10^{\circ}$, $15^{\circ}, 20^{\circ}, 25^{\circ}, 30^{\circ}, 35^{\circ}$ dan $40^{\circ}$, dimana efisiensi tertinggi didapat pada sudut $30^{\circ}$ sebesar $25,5 \%$.

2. Kinerja dari pemodelan pembangkit listrik tenaga mikro hidro yang dibangun masih belum maksimal, dimana torsi dari generator adalah $0,032 \mathrm{Nm}$, sedangkan torsi kincir yang paling tinggi adalah $0,012 \mathrm{Nm}$ pada sudut nozzle $30^{\circ}$. Dari perbandingan torsi generator dengan torsi kincir, dapat diketahui putaran kincir kurang mampu untuk memutar generator secara maksimal.

3. Persentase error dari pemodelan pembangkit listrik tenaga mikro hidro yang dibangun dapat diketahui dari persentase error debit air (Q) serta persentase error ketinggian jatuhnya air $(\mathrm{H})$. Persentase error pemodelan pembangkit listrik tenaga mikro hidro yang dibangun adalah $40 \%$.

\section{REFERENSI}

[1] M T. H. Kristiati. Sumber Energi Penghasil Listrik. Cetakan Pertama.Citra Aji Parama. Yogyakarta. 2011.

[2] D N.K.P. Negara."Kajian Potensi Pengembangan Pembangkit Listrik Tenaga Mikrohidro Memanfaatkan Aliran Sungai Kelampuak di Desa Tamblang-Buleleng”. Bali : Universitas Udayana. 2009.

[3] A. Subandono."Pembangkit Listrik Tenaga Mikro Hidro". Kediri : Universitas Pawyatan Daha Kediri. 2012.

[4] D. Daryanto., Y. Fitrianto. Perencanaan PLTMH Saluran sekunder Kali Logung Desa Sadang, Kecamatan Jekulo, Kudus. 2007
[5] D I. Setiawan. Rancang bangun simulator pembangkit listrik tenaga mikrohidro (PLTMH). 2014

[6] D. Daryanto., Y. Fitrianto. Perencanaan PLTMH Saluran sekunder Kali Logung Desa Sadang, Kecamatan Jekulo, Kudus. 2007

[7] D. Daryanto., Y. Fitrianto. Perencanaan PLTMH Saluran sekunder Kali Logung Desa Sadang, Kecamatan Jekulo, Kudus. 2007

[8] P A. Hendarto."Pemanfaatan pemandian umum untuk pembangkit listrik tenaga mikrohidro (PLTMh) menggunakan kincir tipe overshot". Surakarta : Universitas Muhammadiyah Surakarta. 2012.

[9] F H. Sholihah."Rancang bangun prototipe pembangkit listrik tenaga mikrohidro (PLTMH)". Surabaya : PENS-ITS. 2012

[10] D P. D. Suparyawan., I N. S. Kumara., W G. Ariastina."Studi Perencanaan Pembangkit Listrik Mikrohidro Di Desa Sambangan Kabupaten Buleleng Bali”.Majalah Ilmiah Teknologi Elektro. Vol. 12 No. 2. 2013.

[11] W. Paryatmo. Turbin Air. Yogyakarta : Graha Ilmu. 2007.

[12] P. Oliver."Small hydro power: technology and Current status," Renew. Sustain. Energy Rev. J. Elsevier Sci. Ltd, pp. 537-556, Feb. 2002.

[13] L. Jasa."Mengatasi Krisis Energi Dengan Memanfaatkan Aliran Pangkung Sebagai Sumber Pembangkit Listrik Alternatif'.Majalah Ilmiah Teknologi Elektro. Vol. 9 No. 2. 2010.

[14] L. Jasa."Investigasi sudut Nozzle dan sudut kelengkungan sudu turbin air untuk peningkatan efisiensi mikro hidro”. Surabaya : ITS. 2015. 